\title{
Factors of boreal summer latent heat flux variations over the tropical western North Pacific
}

\author{
Yuqi Wang ${ }^{1,2} \cdot$ Renguang $\mathrm{Wu}^{3,1,4}$
}

Received: 14 February 2021 / Accepted: 1 June 2021 / Published online: 7 June 2021

(C) The Author(s) 2021

\begin{abstract}
Surface latent heat flux (LHF) is an important component in the heat exchange between the ocean and atmosphere over the tropical western North Pacific (WNP). The present study investigates the factors of seasonal mean LHF variations in boreal summer over the tropical WNP. Seasonal mean LHF is separated into two parts that are associated with low-frequency (>90-day) and high-frequency ( $\leq 90$-day) atmospheric variability, respectively. It is shown that low-frequency LHF variations are attributed to low-frequency surface wind and sea-air humidity difference, whereas high-frequency LHF variations are associated with both low-frequency surface wind speed and high-frequency wind intensity. A series of conceptual cases are constructed using different combinations of low- and high-frequency winds to inspect the respective effects of lowfrequency wind and high-frequency wind amplitude to seasonal mean LHF variations. It is illustrated that high-frequency wind fluctuations contribute to seasonal high-frequency LHF only when their intensity exceeds the low-frequency wind speed under which there is seasonal accumulation of high-frequency LHF. When high-frequency wind intensity is smaller than the low-frequency wind speed, seasonal mean high-frequency LHF is negligible. Total seasonal mean LHF anomalies depend on relative contributions of low- and high-frequency atmospheric variations and have weak interannual variance over the tropical WNP due to cancellation of low- and high-frequency LHF anomalies.
\end{abstract}

Keywords Surface latent heat flux $\cdot$ Low-frequency surface wind speed $\cdot$ High-frequency wind intensity $\cdot$ Tropical western North Pacific

\section{Introduction}

Sea surface temperature (SST) changes in the tropical western North Pacific (WNP) play an important role in the climate variability. They induce meridional atmospheric teleconnection pattern over the western Pacific and East Asia

Renguang Wu

renguang@zju.edu.cn

1 Center for Monsoon System Research, Institute of Atmospheric Physics, Chinese Academy of Sciences, Beijing, China

2 College of Earth and Planetary Sciences, University of Chinese Academy of Sciences, Beijing, China

3 Department of Atmospheric Sciences and Key Laboratory of Geoscience Big Data and Deep Resource of Zhejiang Province, School of Earth Sciences, Zhejiang University, Hangzhou, China

4 Southern Marine Science and Engineering Guangdong Laboratory (Zhuhai), Zhuhai, China
(Nitta 1987; Huang and Lu 1989; Huang and Sun 1992; Hu 1997), modulate precipitation in East Asia through anomalous atmospheric circulation (Lu and Dong 2001; Sui et al. 2007) and water vapor transportation from the tropical WNP (Zhou and Yu 2005; Wang and Chen 2012), and affect the intensity and frequency of tropical cyclones over the tropical WNP (Webster et al. 2005; Zhan et al. 2013; Wang and Chen 2018). Anomalous heating associated with the tropical WNP SST anomalies influences the mid-latitude atmospheric circulation and eastern Pacific SST through anomalous Hadley and Walker circulations (Park and An 2014). Understanding the mechanism of SST variations in the tropical WNP helps to improve the knowledge of air-sea coupled variations and seasonal to interannual climate variability in the WNP region (Yoo et al. 2004; Wang et al. 2012).

SST variation is affected by surface heat fluxes, including shortwave radiation, longwave radiation, latent heat flux and sensible heat flux, oceanic advection, and processes associated with diffusion and static instability (Stevenson and Niiler 1983). The SST variation in the tropical WNP 
is dominated by surface heat fluxes and weakly affected by oceanic dynamic processes due to deep thermocline depth and weak horizontal temperature gradient there (Chou et al. 2000). Surface latent heat flux (LHF) is one of the major factors of the interannual SST variation in the tropical WNP (Meyers et al. 1986; Wang et al. 2003; Park et al. 2017). Wang et al. (2003) showed that LHF had a leading contribution to total surface heat flux anomalies and played a fundamental role in generating the large scale dipole SST anomaly pattern in the WNP. Park et al. (2017) identified a larger effect of LHF in the development of the leading mode of tropical WNP SST variation, which showed overall warming or cooling with a center in the subtropical region, than other surface heat flux components (shortwave radiation, longwave radiation, and sensible heat fluxes) and the oceanic heat transport.

The LHF variation is determined by surface wind speed and sea-air humidity difference according to the bulk aerodynamic formula. The interannual variations of atmospheric circulations over the tropical WNP can be modulated by SST anomalies in other oceanic regions (Wang et al. 2003). The accompanying seasonal surface wind speed and humidity variations may induce seasonal LHF anomalies and further provoke variations in local SST (Rasmusson and Carpenter 1982; Deser and Wallace 1990; Wu and Kirtman 2007; Wu et al. 2014). The role of wind-evaporation-SST feedback in the generation and maintenance of seasonal SST and atmospheric circulation anomalies in the tropical WNP has been illustrated in previous studies (Wang et al. 2000, 2003; Wu et al. 2003; Wu et al. 2014; Park et al. 2017).

In addition to seasonal mean atmospheric circulation anomalies, high-frequency atmospheric activities, including synoptic scale variations and intraseasonal oscillations, can contribute largely to seasonal LHF variations over the tropical WNP (Wu 2018; Wang et al. 2020; Wu et al. 2020a). Highfrequency atmospheric activities are strong over the tropical WNP during boreal summer and accompanied by prominent high-frequency surface heat flux variations within their life cycles (Woolnough et al. 2000; Kemball-Cook and Wang 2001; Waliser et al. 2004; Duvel and Vialard 2007). The highfrequency atmospheric variation induced LHF can accumulate in a season and contribute to seasonal SST change (Wu and Cao 2017; Wu 2018; Wang et al. 2020; Wu et al. 2020a, b). Wang et al. (2020) compared the relative contributions of different surface heat fluxes to boreal summer SST change in the tropical WNP. They pointed out that contribution of shortwave radiation to local seasonal SST change exceeded those of total LHF and other surface heat fluxes, but high-frequency component of LHF variation had larger impact than shortwave radiation. Wu (2018) illustrated that the seasonal accumulation of high-frequency wind induced LHF was due to the non-linear dependence of LHF on surface winds over the tropical WNP. Wu et al. (2020a) showed that high-frequency wind-induced
LHFs contributed to both climatological mean and year-toyear variations of seasonal LHF over the WNP and stressed the critical effect of weak surface wind background in the seasonal accumulation of high-frequency LHFs.

The upscale feedback of high-frequency atmospheric activities to seasonal LHF and consequent SST change has prominent year-to-year variation (Wu et al. 2020b). On one hand, both synoptic scale activities and intraseasonal oscillations over the tropical WNP have prominent interannual variations in their intensity due to modulations of atmospheric background fields (Chen and Weng 1998; Teng and Wang 2003; Wu and Song 2018; Zhou et al. 2018; Wang and Wu 2020). On the other hand, weak background surface wind is an important condition for the seasonal accumulation of high-frequency LHF and the interannual variations of low-frequency surface wind over the tropical WNP affect largely the upscale feedback (Wang et al. 2020; Wu et al. 2020b). Both intensity of high-frequency atmospheric variability and low-frequency surface wind are modulated by tropical SST variations, which is indicative of a close relationship between their year-to-year variations. The observational studies of Wang et al. (2020) and Wu et al. (2020a, b) have shown the effects of both seasonal mean background wind and high-frequency wind intensity on the high-frequency LHF variations. However, due to the interrelationship between them, the individual effects of low- and high-frequency wind variations on the high-frequency LHF cannot be determined based on the observations and thus deserve further investigation. In this study, we construct a series of combinations of low- and high-frequency wind variations to address this issue.

In the present study, we decompose seasonal LHF into low- and high-frequency components, which are related to low- and high-frequency atmospheric variations, respectively, and investigate factors of variations of seasonal mean LHF components in boreal summer over the tropical WNP. The organization of the rest of the text is as follows. Datasets and methods used in the study are described in Sect. 2. In Sect. 3, we demonstrate interannual variations of low- and high-frequency LHFs in boreal summer over the tropical WNP, and their relationships with local seasonal SST change. In Sect. 4, we examine the factors of seasonal low- and high-frequency LHFs. In Sect. 5, we construct a series of conceptual cases using different combinations of low- and high-frequency winds to demonstrate their effects on seasonal accumulated LHFs separately. Summary and discussions are given in Sect. 6.

\section{Data and Methods}

The present study uses daily surface heat fluxes, including LHF, surface wind stress, wind speed at $10 \mathrm{~m}$, specific humidity at $2 \mathrm{~m}$, and SST obtained from the TropFlux 
dataset (Kumar et al. 2012) (https://incois.gov.in/tropflux/). The TropFlux variables are available on a $1^{\circ} \times 1^{\circ}$ grid over the global tropical ocean $\left(30^{\circ} \mathrm{N}-30^{\circ} \mathrm{S}\right)$ from January 1979 to December 2018. Upward surface heat fluxes are defined as positive values. Zonal and meridional surface winds are calculated using surface wind stress and wind speed:

$u_{x}=\frac{\tau_{x}}{\tau} \times w s d \quad u_{y}=\frac{\tau_{x}}{\tau} \times w s d$,

where $u_{x}$ and $u_{y}$ are zonal and meridional surface wind, $\tau_{x}$ and $\tau_{y}$ are zonal and meridional wind stress, $\tau$ is the magnitude of surface wind stress, and $w s d$ is wind speed at $10 \mathrm{~m}$.

The present study distinguishes the effects of low-frequency and high-frequency atmospheric variations on seasonal LHF and SST change in boreal summer. Following Wang et al. (2020), variables including LHF, surface wind speed and air-sea humidity difference are decomposed into low-frequency ( $>90$-day) and high-frequency ( $\leq 90$-day) components. Low-frequency component mainly reflects interannual variations of the variables, with the periods above 91 days and within 10 years. High-frequency component consists of variations with periods within 90 days, including intraseasonal oscillation and synoptic scale variations. As for zonal and meridional surface wind, SST, and specific humidity, the low-frequency components are calculated as 91-day running mean of the daily data. The low-frequency components obtained using our method are highly consistent with those obtained by a 91-day Lanczos low-pass filtering (figures not shown). The corresponding high-frequency components are obtained by original daily data minus the low-frequency components. LHF is estimated based on the bulk formula:

$\mathrm{LHF}=\rho_{a} C_{e} L\left|\vec{V}_{\text {low }}+\vec{V}_{\text {high }}\right|\left[q_{s}\left(S S T_{\text {low }}+S S T_{\text {high }}\right)-\left(q_{a_{\text {low }}}+q_{a_{\text {high }}}\right)\right]$,

where $\rho_{a}$ is the surface air density, $C_{e}$ is the latent heat exchange coefficient, $L$ is latent heat of condensation, and $q_{s}$ is the saturation specific humidity at SST. Subscripts "low" and "high" represent low- and high-frequency components, respectively. $C_{e}$ is calculated using original daily LHF, surface wind speed, SST, and surface air humidity to allow the recovery of total LHF. We note that the exchange coefficient $\mathrm{C}_{\mathrm{e}}$ is a complicated function of atmospheric stability and roughness length (Fairall et al. 1996) and it is hard to decompose it into low- and high-frequency components. The range of $C_{e}$ is basically within $1.0-1.8 \times 10^{-3}$ (Pond et al. 1974). We have conducted a parallel decomposition analysis using a constant $C_{e}$ value $\left(1.6 \times 10^{-3}\right)$. The obtained LHF components display quite similar interannual variations and spatial distributions with some differences in the magnitude of LHF anomalies. The above formula of LHF indicates a nonlinear relationship of LHF to surface wind and SST. In the present study, we decompose the total LHF as follows:

$\mathrm{LHF}_{\text {low }}=\rho_{a} C_{e} L\left|\vec{V}_{\text {low }}\right|\left[q_{s}\left(S S T_{\text {low }}\right)-q_{a_{\text {low }}}\right]$

$\mathrm{LHF}_{\text {high }}=\mathrm{LHF}-\mathrm{LHF}_{\text {low }}$.

Low-frequency LHF is derived from low-frequency components of surface wind, SST and surface specific humidity. High-frequency LHF is calculated as the difference between the total and low-frequency LHF. Similarly, the surface wind speed and humidity difference between sea surface and surface air are also decomposed into low- and high-frequency components:

$w s d_{\text {low }}=\sqrt{u_{\text {low }}^{2}+v_{\text {low }}^{2}} w s d_{\text {high }}=w s d-w s d_{\text {low }}$

$\Delta q_{\mathrm{low}}=q_{s}\left(S S T_{\mathrm{low}}\right)-q_{a_{\mathrm{low}}} \Delta q_{\mathrm{high}}=q_{s}(S S T)-q_{a}-d q_{\mathrm{low}}$.

In the above decomposition method, high-frequency LHF is calculated using original observed daily LHF minus the calculated low-frequency LHF. High-frequency LHF is not directly calculated using high-frequency components of surface wind, SST and surface air humidity as the LHF component calculated using this method only represents a part of LHF variation induced by high-frequency atmospheric activities. Due to nonlinear relationship between LHF and the input variables, there are also LHF variations that are associated with both high-frequency and low-frequency atmospheric variations. In our decomposition method, the high-frequency LHF contains all LHF variations that are related to high-frequency atmospheric activities.

In the present study, seasonal mean LHF, surface wind speed and air-sea humidity difference components in boreal summer are calculated as June-July-August (JJA) mean of corresponding daily variables. SST change in boreal summer is calculated as the difference of 31-day mean SST from August 16 to September 15 minus that from May 17 to June 16 to smooth out high-frequency variations. Interdecadal and longer time-scale variations ( $>10$-year) of all variables are removed from the JJA mean time series by applying a 10-year running mean to the original time series. The significance level of correlation coefficient is estimated based on the Student $t$ test. The critical value of correlation coefficient at the $95 \%$ confidence level is 0.312 for 40 independent samples according to the Student $t$ test. 


\section{Interannual Variations of Low- and High-Frequency LHFs}

Atmospheric variations over the tropical WNP are complicated, consisting of components of different time scales. On one hand, interannual SST anomalies, especially in tropical oceans, can provoke prominent interannual variations in surface wind, humidity and other related atmospheric fields over the tropical WNP (Wang et al. 2000; Lau and Nath 2000; Xie et al. 2009). On the other hand, atmospheric intraseasonal oscillations and synoptic scale variations over the tropical WNP in boreal summer are very prominent (Teng and Wang 2003; Liu et al. 2016; Wu and Song 2018), accompanied by large high-frequency perturbations in surface heat fluxes and oceanic fields $(\mathrm{Wu}$ et al. 2020a, b). To understand different effects of these atmospheric variations on LHF, we decompose total LHF into low- and high-frequency components, which represent LHF variations associated with low-frequency (90-day to 10-year) and high-frequency (less than 90-day) atmospheric activities, respectively, and analyze their interannual variations.

El Niño-Southern Oscillation (ENSO) is one major factor of both interannual and high-frequency atmospheric variations over the tropical WNP (Wang et al. 2000, 2003, 2020; Wu et al. 2014; Wu and Cao 2017; Wu and Song 2018). Our analysis found that JJA mean LHF anomalies over the tropical WNP may be opposite in different El Niño years. We select two El Niño developing years, 1997 and 2002, as examples to illustrate this feature and to help to understand the reason. Spatial distributions of
JJA mean total, low-frequency, high-frequency LHFs and corresponding interannual anomalies in these two years are displayed in Figs. 1 and 2.

In boreal summer of 1997, total LHF is positive over the tropical WNP, with a relatively small value over the subtropical WNP and a large value near the equator (Fig. 1a). Low-frequency LHF is large in a region extending southeastward from the South China Sea (SCS) to equatorial western Pacific and in the subtropical North Pacific, where total LHF is mainly contributed by the low-frequency component (Fig. 1b). Low-frequency LHF is relatively small over a southeast-to-northwest tilted strip from the equatorial central Pacific to subtropical WNP. JJA mean high-frequency LHF has a prominent contribution to total LHF over the above strip, with the center value exceeding the low-frequency LHF (Fig. 1c). Negative (though small) high-frequency LHF values are observed over the equatorial western Pacific and subtropical North Pacific, indicative of damping effect of high-frequency atmospheric activities on seasonal LHFs. Seasonal mean anomalies of low- and high-frequency LHFs are opposite over the tropical WNP (Figs. 1e, f). Lowfrequency LHF has positive anomalies over the equatorial western Pacific and negative anomalies over the equatorial central Pacific and subtropical WNP. The high-frequency LHF anomalies are mostly opposite, with values smaller than those of low-frequency LHF anomalies. The spatial distribution of JJA mean total LHF anomalies is basically consistent with low-frequency LHF anomalies, negative in most regions of the tropical WNP but with smaller values (Fig. 1d).

In boreal summer of 2002, the spatial distributions of low- and high-frequency LHFs bear similarity to those in
Fig. 1 JJA mean a total, b lowfrequency and $\mathbf{c}$ high-frequency LHFs $\left(\mathrm{W} / \mathrm{m}^{2}\right)$ and $\mathbf{d}-\mathbf{f}$ the corresponding anomalies in 1997
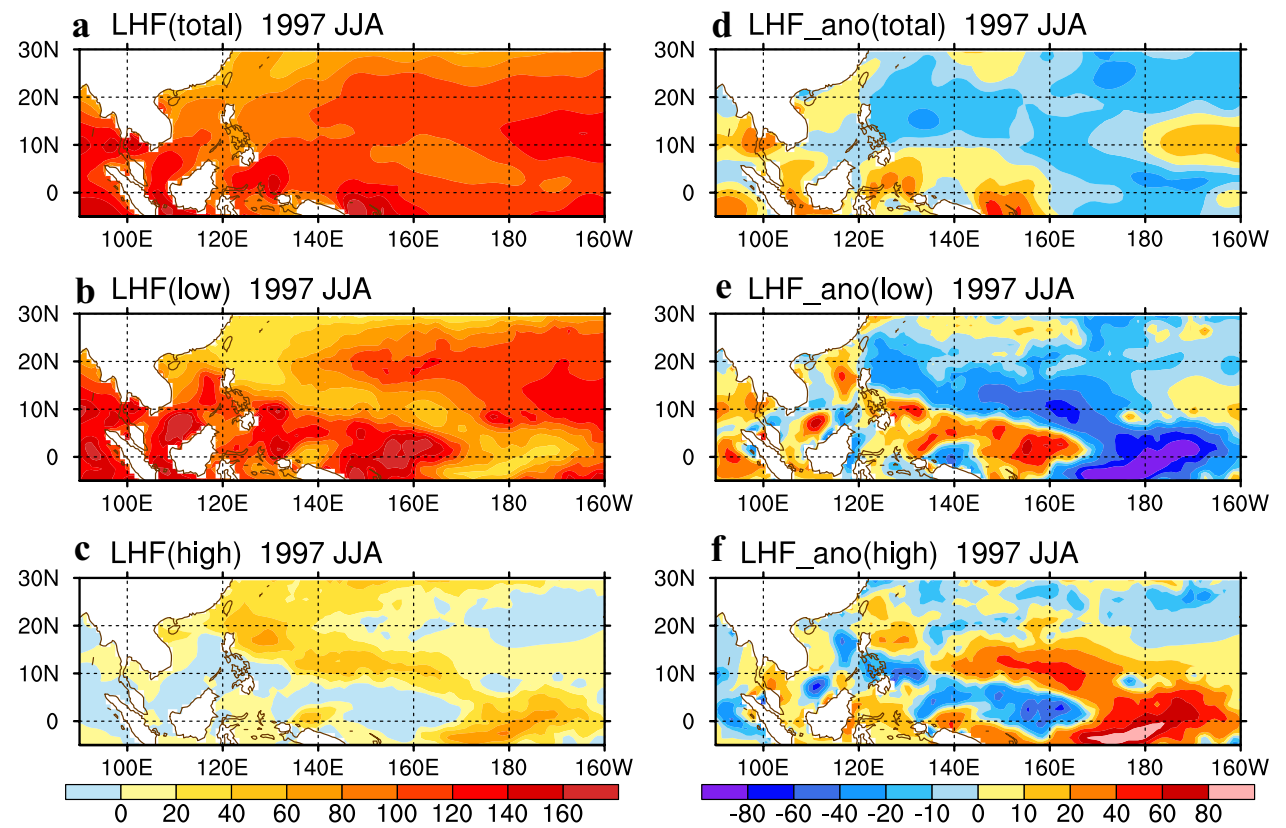
Fig. 2 Similar to Fig. 1 except for LHFs in 2002

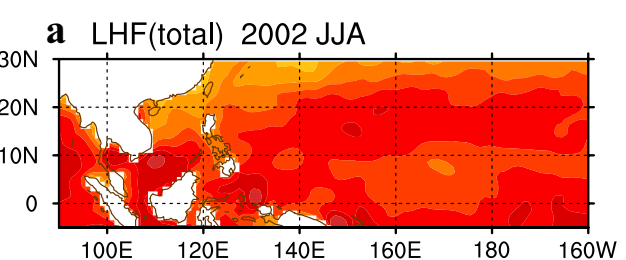

d LHF_ano(total) $2002 \mathrm{JJA}$

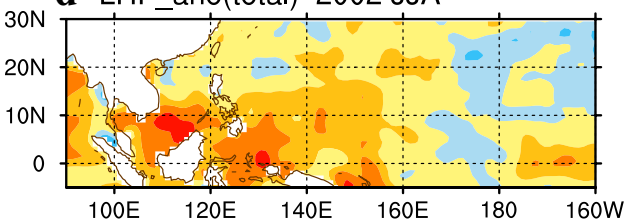

b LHF(low) 2002 JJA
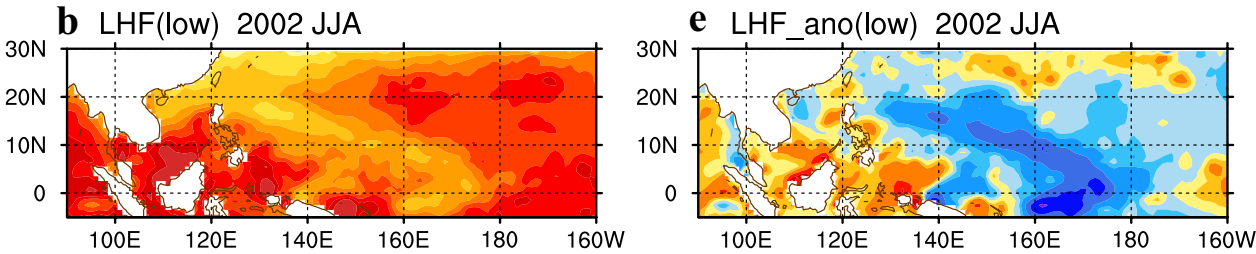

c $\operatorname{LHF}$ (high) $2002 \mathrm{JJA}$

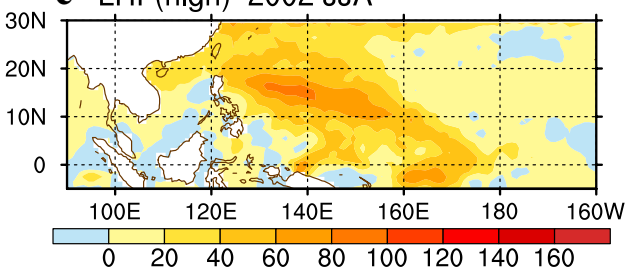

f LHF_ano(high) $2002 \mathrm{JJA}$

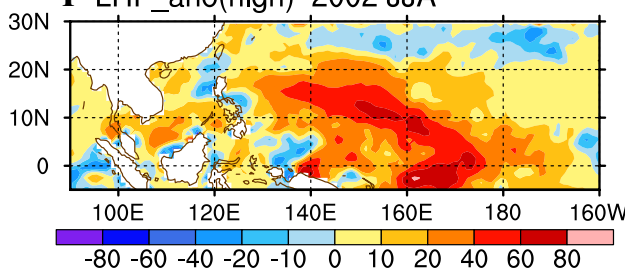

summer of 1997. Large positive high-frequency LHF covers most regions of the tropical WNP, with center values exceeding the low-frequency LHFs (Fig. 2b, c). Lowfrequency LHF anomalies show a west-east contrast, and high-frequency LHF anomalies are mostly positive over the tropical WNP (Fig. 2e, f). Different from summer of 1997, total LHF anomalies are mostly positive in summer of 2002, which are dominated by low-frequency LHF over the equatorial western Pacific and by high-frequency LHF over the other regions of the tropical WNP (Fig. 2d).

Low- and high-frequency LHF variations in boreal summers of 1997 and 2002 reflect some typical features in El Niño developing stages. In both years, there are opposite low-frequency and high-frequency LHF anomalies over the tropical WNP. However, the total LHF anomalies tend to be opposite over most of the tropical WNP in these two years. This difference is related to the relative magnitude of low- and high-frequency LHF anomalies. We select a key region $\left(10^{\circ} \mathrm{N}-15^{\circ} \mathrm{N}, 145^{\circ} \mathrm{E}-155^{\circ} \mathrm{E}\right)$ to illustrate the relative contributions of low- and high-frequency LHFs to total LHF variation over the tropical WNP. In this region, highfrequency LHF is relatively large and both low- and highfrequency LHFs have large anomalies in boreal summers of 1997 and 2002 (Figs. 1, 2). Both low- and high-frequency LHFs have larger interannual variations than total LHF, and their anomalies are mostly opposite (Fig. 3a). This indicates that low- and high-frequency atmospheric activities have different effects on interannual variations of seasonal LHF over the tropical WNP.

As LHF is one of the major factors of seasonal SST change in tropical WNP (Meyers et al. 1986; Wang et al. 2003; Park et al. 2017), we examined the relationships of
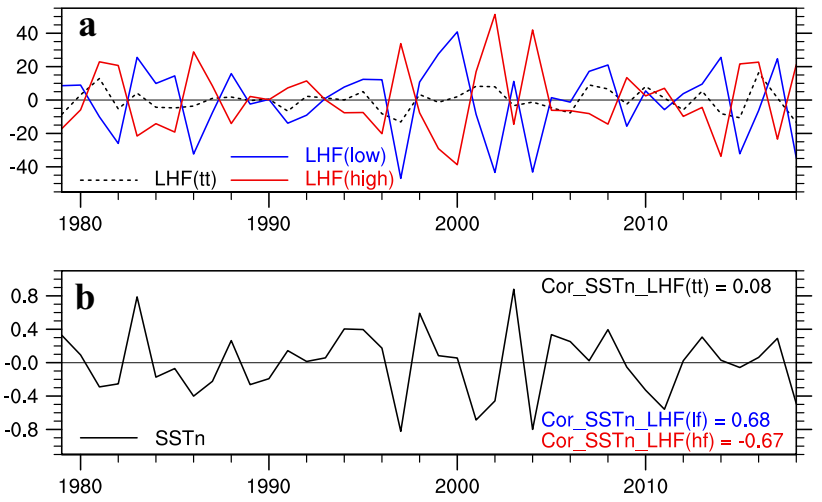

Fig. 3 Area-mean a JJA mean total (black line), low-frequency (blue line), high-frequency (red line) LHF anomalies $\left(\mathrm{W} / \mathrm{m}^{2}\right)$, and $\mathbf{b}$ JJA SST change $\left({ }^{\circ} \mathrm{C}\right)$ anomalies averaged in the region of $10^{\circ}-15^{\circ} \mathrm{N}$ and $145^{\circ}-155^{\circ} \mathrm{E}$. The values at the right are correlation coefficients between JJA SST change and total, low- and high-frequency LHFs

LHF components with local SST change in the tropical WNP (Fig. 3b). The significant positive correlation (0.68) between JJA SST change and upward low-frequency LHF reflects that SST warming/cooling tends to be accompanied by stronger/ weaker surface evaporation. This indicates a damping effect of low-frequency atmospheric variability on seasonal SST change in the tropical WNP through LHF. In contrast, there is a significant negative correlation $(-0.67)$ between JJA SST change and high-frequency LHF in this region. It indicates that larger/smaller seasonal mean upward highfrequency LHF is favorable for local SST cooling/warming in summer. Such upscale feedback of high-frequency atmospheric activities on seasonal SST change has been unraveled in previous studies (Wu 2018; Wang et al. 2020). Due to 
opposite variations of low- and high-frequency LHFs, total LHF over the tropical WNP in summer has a relatively small interannual variability and is weakly correlated with local SST change (correlation coefficient of 0.08).

Above analysis shows that both low- and high-frequency atmospheric activities have prominent effects on seasonal LHF variations and SST change in the tropical WNP. The LHF anomalies induced by high-frequency atmospheric variability can cancel seasonal mean LHF anomalies associated with low-frequency atmospheric variability. Total LHF anomalies actually represent the residual of the opposite effects of low- and high-frequency atmospheric variability so that the statistical relationship between seasonal total LHF and local SST change has little physical meaning. This confirms the necessity of distinguishing atmospheric variability on different time scales when analyzing their effects on seasonal LHF and SST variations.

\section{Factors of Seasonal Low- and High-Frequency LHF Variations}

Surface LHF variation relies on both surface air condition and SST. According to the bulk formula, upward LHF increases with the enhancement of local sea-air humidity difference and surface wind speed. Previous section shows that low- and high-frequency atmospheric variations have different effects on seasonal LHF over the tropical WNP. In this section, we decompose surface wind speed and sea-air humidity difference into low- and high-frequency components and examine their contributions to seasonal low- and high-frequency LHF variations.

Figure 4 shows the year-to-year variations of JJA mean low- and high-frequency surface wind speed and sea-air humidity difference averaged in the region of $10^{\circ}-15^{\circ} \mathrm{N}$ and $145^{\circ}-155^{\circ} \mathrm{E}$. Here, high-frequency components of surface wind speed and sea-air humidity difference refer to those induced by high-frequency atmospheric activities. The magnitude of anomalies of JJA mean high-frequency sea-air humidity difference is obviously smaller than that of the lowfrequency component (Fig. 4a). In contrast, JJA mean lowand high-frequency surface wind speed anomalies have comparable magnitude with a significant negative correlation $(-0.76)$ (Fig. 4b). This indicates that seasonal accumulated surface wind speed anomalies induced by high-frequency atmospheric activities over the WNP tend to be larger when the low-frequency surface wind is weaker. Correlation coefficients of decomposed LHFs with the corresponding components of sea-air humidity difference and surface wind speed over the tropical WNP are calculated to inspect relative contributions of sea-air humidity difference and surface wind speed. The low-frequency LHF variation is contributed by both low-frequency sea-air humidity difference and
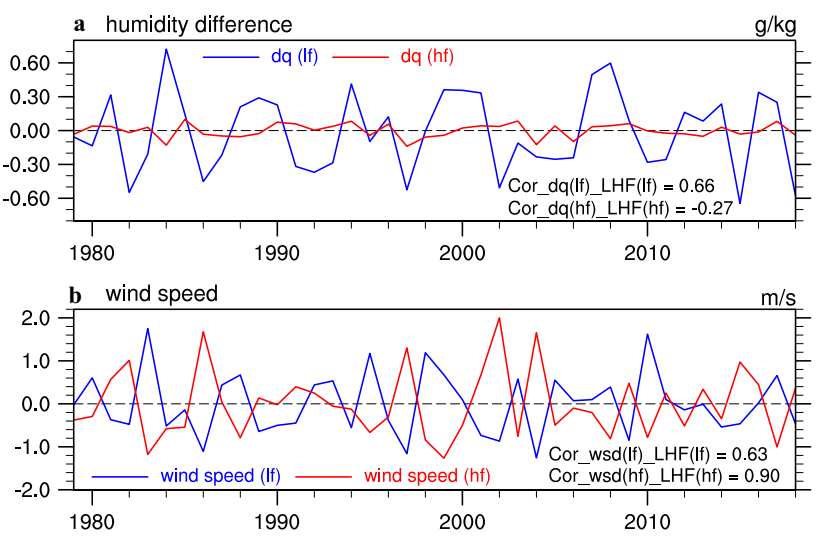

Fig. 4 JJA mean low-frequency (blue lines) and high-frequency (red lines) a sea-air humidity difference $(\mathrm{g} / \mathrm{kg})$ and $\mathbf{b}$ surface wind speed $(\mathrm{m} / \mathrm{s})$ anomalies averaged in the region of $10^{\circ}-15^{\circ} \mathrm{N}$ and $145^{\circ}-155^{\circ} \mathrm{E}$. The values at the bottom right are correlation coefficients between low- and high-frequency sea-air humidity difference or surface wind speed and corresponding LHF components

surface wind speed, with comparable significant positive correlation coefficients of 0.66 and 0.63 , respectively. The high-frequency LHF variation is dominated by the highfrequency surface wind speed variation, with a correlation coefficient of 0.90 , while the high-frequency sea-air humidity difference has a small impact on the LHF variation.

The influence of high-frequency wind variability on seasonal mean surface LHF over the tropical WNP has been unraveled in previous studies (Wang et al. 2020; Wu et al. 2020a, b). These studies have shown that the high-frequency wind-induced seasonal LHF anomalies depend upon two factors. One is the low-frequency surface wind background that plays a critical role in the seasonal accumulation of high-frequency LHF anomalies. This is due to the non-linear dependence of daily LHF on high-frequency wind variability under the condition of weak low-frequency surface wind speed (Wu 2018; Wu et al. 2020a). When low-frequency wind speed is small, both westerly and easterly phases of high-frequency wind variations may enhance surface wind speed and consequently contribute to surface evaporation so that the high-frequency LHF anomalies can accumulate in the whole season. In this way, interannual variations of low-frequency surface wind speed can modulate the effect of high-frequency atmospheric activities on seasonal LHF variation. The other factor is that the intensity of high-frequency wind fluctuations that has large interannual variations over the tropical WNP due to the modulation of El Niño and La Niña events (Wu and Cao 2017; Wang and Wu 2020). Highfrequency wind intensity represents the amplitude of daily high-frequency wind variations. A larger high-frequency wind intensity induces more LHF and thus contributes to larger seasonal accumulated high-frequency LHF anomalies (Wu et al. 2020a, b). 
Relationships of seasonal high-frequency LHF to the above two factors over the tropical WNP in summer are illustrated in Fig. 5a,b. High-frequency wind intensity is measured by JJA mean kinetic energy of daily high-frequency surface winds. The seasonal high-frequency LHF is larger when low-frequency surface wind speed is smaller and when high-frequency wind intensity is stronger. So, weak low-frequency surface wind background and strong high-frequency wind intensity are favorable conditions for the increase of seasonal mean high-frequency LHF over the tropical WNP. The correlation coefficient of seasonal high-frequency LHF with low-frequency wind speed and high-frequency wind intensity is -0.53 and 0.84 , respectively, during $1979-2018$. Notice that JJA mean low-frequency surface wind speed and high-frequency wind intensity variations are not independent, with a large negative correlation $(-0.74$; Fig. $5 c)$. Under the effect of ENSO events, positive/negative low-frequency surface wind speed anomalies tend to be co-located with negative/positive high-frequency wind intensity anomalies over the tropical WNP. Individual effects of these two factors are examined separately in Sect. 5.

Spatial distributions of JJA mean low-frequency surface wind speed and high-frequency wind intensity in 1997 and 2002 are displayed in Figs. 6 and 7 to examine their correspondence to seasonal LHF anomalies in these two years
(Figs. 1, 2). In boreal summer of 1997, the monsoon trough, which is represented by the zero zonal wind line (black solid line in Fig. 6), extends eastward to the east of $180^{\circ}$ compared to its climatological position (black dash line). JJA mean low-frequency surface wind speed anomalies show a west-east contrasting pattern across the monsoon trough, with positive anomalies located over the equatorial western Pacific and southeastern Philippine Sea, and negative anomalies extending from equatorial central Pacific to subtropical WNP (Fig. 6c). High-frequency wind intensity is large over subtropical WNP (Fig. 6b). Positive high-frequency wind intensity anomalies are located in a narrow band over the tropical WNP, which is in good correspondence with the position of JJA mean monsoon trough (Fig. 6d).

Comparing high-frequency LHF anomalies in summer of 1997 (Fig. 1f) with anomalies of the two factors (Fig. 6c,d), we can see that the spatial distribution of highfrequency LHF anomalies over the tropical WNP is similar to that of low-frequency surface wind speed anomalies. Opposite anomalies of low-frequency surface wind speed across the monsoon trough can explain the west-east contrast of high-frequency LHF anomalies south of $15^{\circ} \mathrm{N}$. The high-frequency wind intensity has a supplementary effect to seasonal high-frequency LHF anomalies along the monsoon trough. In summer of 2002, the low-frequency surface
Fig. 5 Scatter plot of JJA a low-frequency surface wind speed $(\mathrm{m} / \mathrm{s})$ and high-frequency LHF $\left(\mathrm{W} / \mathrm{m}^{2}\right)$, b kinetic energy of high-frequency wind $\left(\mathrm{m}^{2} / \mathrm{s}^{2}\right)$ and high-frequency LHF, c lowfrequency surface wind speed and kinetic energy of high-frequency surface wind averaged in the region of $10^{\circ}-15^{\circ} \mathrm{N}$ and $145^{\circ}-155^{\circ} \mathrm{E}$ during $1979-2018$

Fig. 6 JJA mean a lowfrequency surface wind speed $(\mathrm{m} / \mathrm{s})$, b kinetic energy of highfrequency surface wind $\left(\mathrm{m}^{2} /\right.$ $\mathrm{s}^{2}$ ) and $\mathbf{c}-\mathbf{d}$ the corresponding anomalies in 1997. Black dash and solid lines denote zero lowfrequency zonal wind of JJA mean climatology and in JJA of 1997, respectively
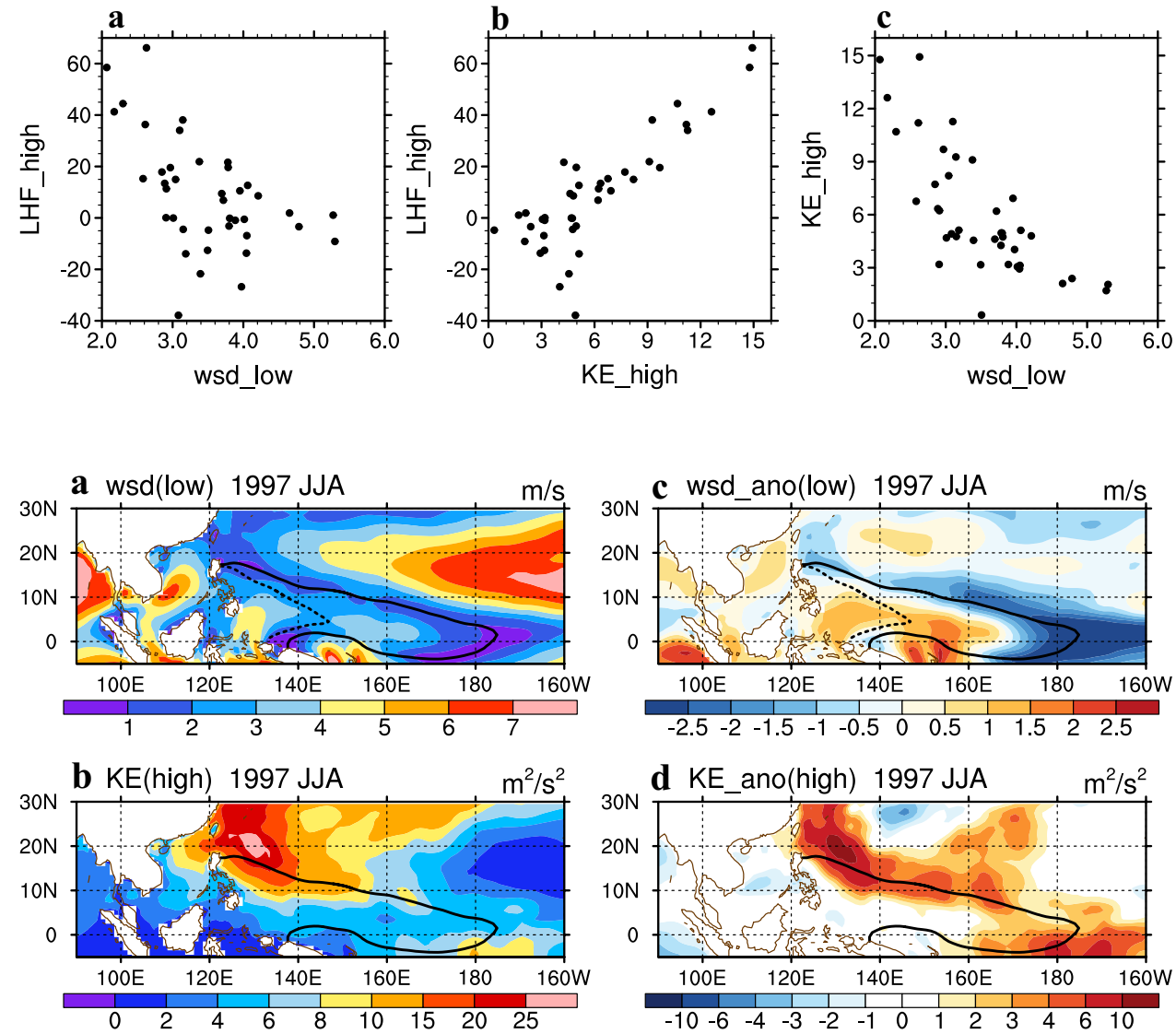
Fig. 7 Similar to Fig. 6 except for those in 2002
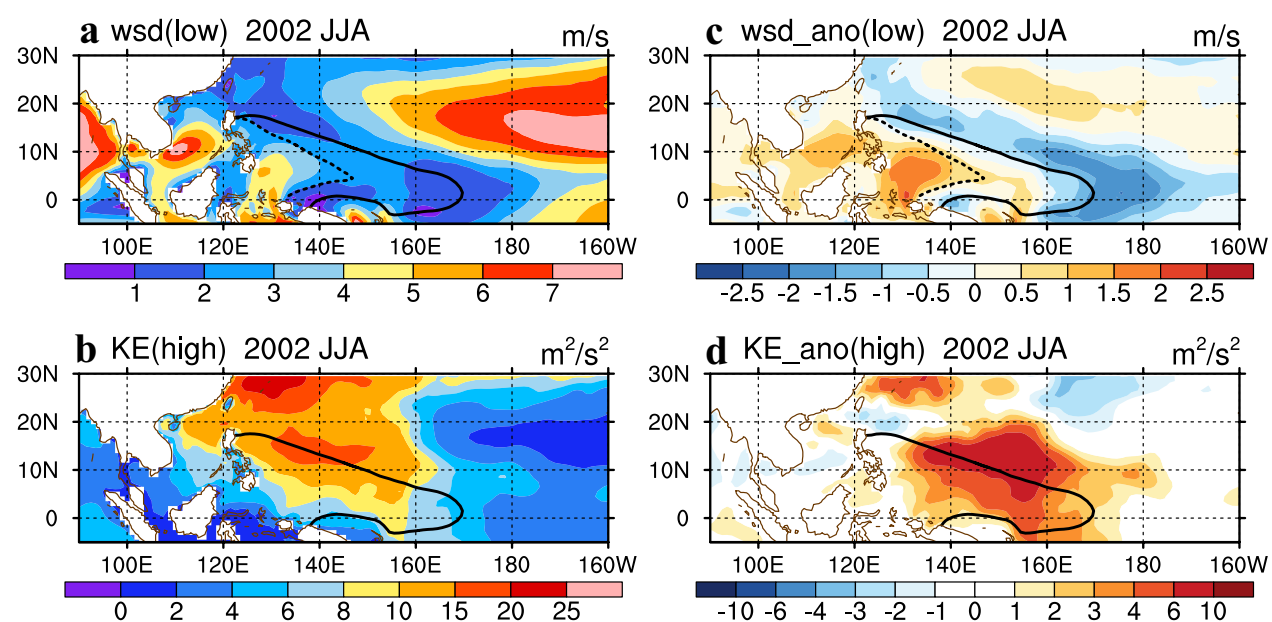

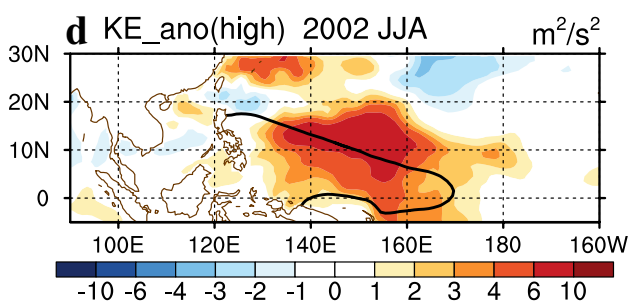

wind speed anomalies are positive over southern SCS and southeast of the Philippines, and negative from equatorial central Pacific to the subtropical WNP (Fig. 7c). The spatial distribution of low-frequency surface wind speed anomalies is similar to that in summer of 1997 . Values of lowfrequency surface wind speed anomalies are smaller and the eastward extension of the monsoon trough (black solid lines in Fig. 7) is also less prominent compared to summer of 1997. High-frequency wind intensity is large over the subtropical WNP and eastern Philippine Sea (Fig. 7b). The positive anomalies of high-frequency wind intensity cover a wide area over the tropical WNP (Fig. 7d). Different from summer of 1997, high-frequency wind intensity anomalies have prominent effects on high-frequency LHF anomalies in summer of 2002 (Fig. 2f). The positive high-frequency LHF anomalies over the tropical WNP are mainly contributed by high-frequency wind intensity anomalies, and those over the equatorial central Pacific are determined by negative lowfrequency surface wind speed anomalies.

In the above analysis, the variations of low-frequency surface wind speed and high-frequency wind intensity are similar in boreal summers of 1997 and 2002, both of which are El Niño events. During El Niño developing summers, anomalous low-frequency westerly winds are induced over the tropical Pacific, decreasing low-frequency surface wind speed east of the monsoon trough. At the same time, seasonal atmospheric background fields associated with tropical SST variations, including anomalous low-level cyclone, ascending motion and easterly vertical shear of zonal winds over the tropical western Pacific, are favorable for intensifying high-frequency wind variability. Therefore, these two factors together enhance the upscale feedback of highfrequency atmospheric activities to seasonal LHF during El Niño developing summers. In La Niña developing summers, the stronger surface wind background and weaker high-frequency wind intensity are unfavorable for seasonal accumulation of high-frequency LHFs.

\section{Individual Effects of Low- and High-Frequency Winds on Seasonal LHFs}

In previous sections, we have noted a close relationship between JJA mean low- and high-frequency surface wind speed over the tropical WNP (Fig. 5c). An issue is individual impacts of low-frequency surface wind background and high-frequency wind intensity on seasonal LHF variation. The individual impacts cannot be determined based on the observations as the low-frequency wind and high-frequency wind intensity variations are closely related to each other. In this section, we construct a series of conceptual cases with different combinations of low- and high-frequency winds and calculate the corresponding seasonal LHFs using the bulk formula. This helps to understand the dependence of seasonal mean high-frequency LHF anomalies on low-frequency wind and high-frequency wind intensity separately.

We first examine the magnitude of low and high-frequency wind variations over the tropical WNP. Figure 8 shows the probability density function of area-mean daily low- and high-frequency surface zonal winds averaged in the region of $5^{\circ} \mathrm{N}-10^{\circ} \mathrm{N}$ and $145^{\circ} \mathrm{E}-150^{\circ} \mathrm{E}$ in boreal summers of 1979-2018. A small region is selected to avoid the canceling of high-frequency winds in different phases. The low-frequency wind varies mostly within -5 to $5 \mathrm{~m} / \mathrm{s}$, and easterly winds appear to be more frequent than westerly winds (Fig. 8a). Since the variation of low-frequency wind is relatively smooth, we use a series of constants, varying from -5 to $5 \mathrm{~m} / \mathrm{s}$ with an interval of $0.5 \mathrm{~m} / \mathrm{s}$, to represent different cases of low-frequency winds. The highfrequency wind varies mostly within -8 to $8 \mathrm{~m} / \mathrm{s}$, with the center of probability density function near zero (Fig. 8b). We use sine functions with different amplitudes (varying from 0 to $8 \mathrm{~m} / \mathrm{s}$ with an interval of $1 \mathrm{~m} / \mathrm{s}$ ) to represent the high-frequency wind variations. A larger amplitude indicates larger high-frequency wind intensity. Three typical 
Fig. 8 Probability density functions (\%) of area-mean daily a low-frequency and $\mathbf{b}$ high-frequency zonal wind $(\mathrm{m} / \mathrm{s})$ in June 1 to August 31 of 1979-2018 averaged in the region of $5^{\circ}-10^{\circ} \mathrm{N}$ and $145^{\circ}-150^{\circ} \mathrm{E}$
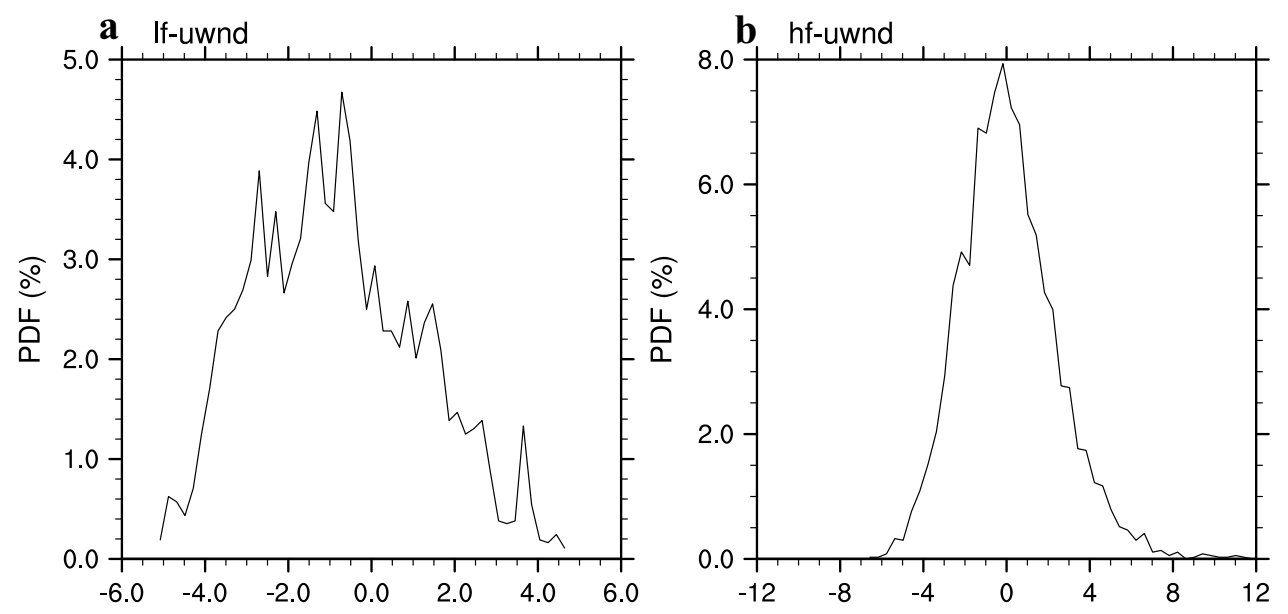

periods (5, 15 and 30 days) of high-frequency wind variations in boreal summer over the tropical WNP are selected as the periods of the sine functions. Then, daily total LHF is calculated using the bulk formula:

$\mathrm{LHF}_{\text {total }}=\rho_{a} C_{e} L\left|\vec{V}_{\text {low }}+\vec{V}_{\text {high }}\right|\left(q_{s}-q_{a}\right)$.

Here, we only discuss the influence of surface wind speed on LHF. So, $\rho_{a}, L, q_{s}$ and $q_{a}$ are represented by observed JJA mean climatology averaged in the region of $5^{\circ}-10^{\circ} \mathrm{N}$ of $145^{\circ}-150^{\circ} \mathrm{E}$. The exchange coefficient $C_{e}$ is calculated using area-mean climatological LHF, total surface wind speed, $\rho_{a}, L, q_{s}$ and $q_{a}$. The total LHF is decomposed into low- and high-frequency components as follows:

$$
\begin{aligned}
& \mathrm{LHF}_{\text {low }}=\rho_{a} C_{e} L\left|\vec{V}_{\text {low }}\right|\left(q_{s}-q_{a}\right) \\
& \mathrm{LHF}_{\text {high }}=\mathrm{LHF}_{\text {total }}-\mathrm{LHF}_{\text {low }} .
\end{aligned}
$$

Seasonal mean LHFs are represented by 90-day averaged daily LHF components.
We now examine the seasonal mean LHFs. The 90-day averaged LHFs are the same for the high-frequency winds with a period of 5, 15 or 30 days. So, seasonal mean LHF is not affected by the period of high-frequency wind variations. Figure 9 displays the variations of 90-day averaged LHF components with different combinations of low-frequency wind (x-axis) and high-frequency wind amplitude (y-axis). The total LHF is non-linearly related to both low-frequency wind and high-frequency wind amplitude (Fig. 9a). These non-linear relationships are more clear when total LHF is decomposed into low- and high-frequency components. The seasonal low-frequency LHF increases with the enhancement of both positive and negative low-frequency winds (Fig. 9b). The seasonal high-frequency LHF is affected by both low-frequency wind and high-frequency wind amplitude (Fig. 9c), which is consistent with the previous statistical analysis (Wang et al. 2020; Wu et al. 2020a, b). Notice that seasonal high-frequency LHF is zero in some cases, so the contribution of high-frequency winds to total LHF depends upon the combination of low-frequency wind and high-frequency wind amplitude.

We then analyze the individual influence of low-frequency wind and high-frequency wind amplitude on seasonal LHFs
Fig. 9 90-day averaged a total, b low-frequency and $\mathbf{c}$ high-frequency LHF $\left(\mathrm{W} / \mathrm{m}^{2}\right)$ calculated using different low-frequency winds (varying from -5 to $5 \mathrm{~m} / \mathrm{s}$ ) and high-frequency winds with different amplitudes (varying from 0 to $8 \mathrm{~m} / \mathrm{s}$ )
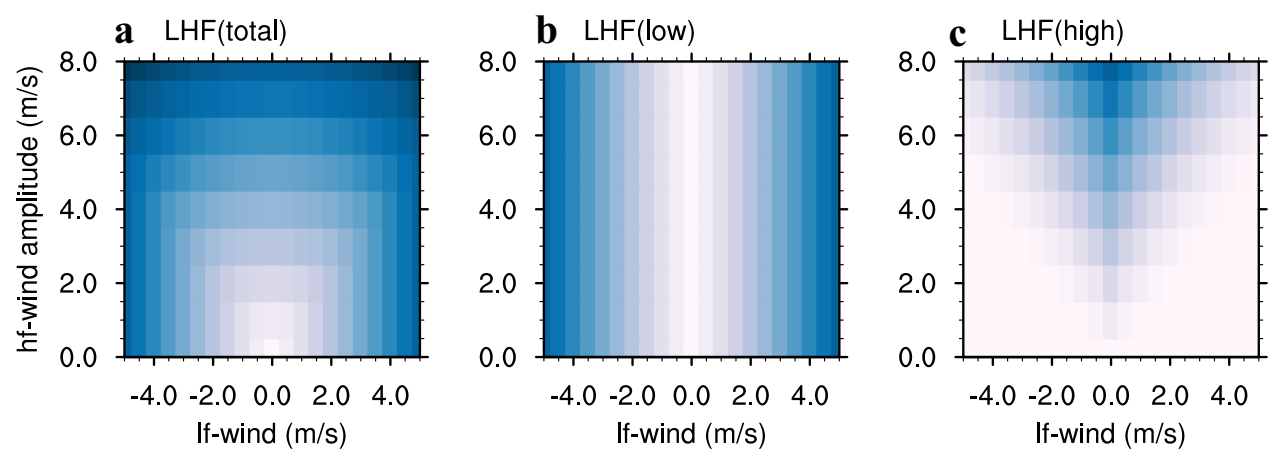

$0 \quad 25$

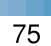


separately. For this purpose, we fix one of them to display the LHF variations with the other factor. Figure 10 shows the relationships between the LHF components and lowfrequency wind with the high-frequency wind amplitude fixed at a specific value $(0,2,4,6,8 \mathrm{~m} / \mathrm{s})$. Upward lowfrequency LHF (black squares in Fig. 10a) increases linearly with the enhancement of low-frequency wind in both positive and negative directions. Seasonal high-frequency LHF (triangles in Fig. 10a) can be modulated by low-frequency wind even with the high-frequency wind amplitude fixed. When low-frequency wind speed exceeds the amplitude of high-frequency wind variability, the seasonal mean highfrequency LHF is zero and the total LHF is entirely contributed by the low-frequency component. This is because the high-frequency LHFs induced by high-frequency winds are opposite when the high-frequency winds are in opposite directions so that they cancel each other in a season. When low-frequency wind speed is smaller than high-frequency wind amplitude, the seasonal mean high-frequency LHF increases with the weakening of low-frequency wind in both positive and negative low-frequency wind cases. Therefore, the high-frequency LHF contributes to seasonal total LHF, particularly, when the low-frequency wind speed is small. Nevertheless, with the increase of low-frequency wind speed, the decrease of high-frequency LHF is always smaller than the increase of low-frequency LHF (Fig. 10a). So, total seasonal LHF increases monotonously with the enhancement of low-frequency wind speed (Fig. 10b).

The dependence of seasonal LHF on high-frequency wind amplitude is further displayed in Fig. 11 when the lowfrequency wind is fixed at a specific value $(0,2$ or $-2,5$ or $-5 \mathrm{~m} / \mathrm{s}$ ). As seasonal low-frequency LHF is independent of high-frequency wind amplitude, so only high-frequency and total LHFs are displayed. Consistent with the preceding analysis, the impact of high-frequency wind on seasonal LHF is associated with the low-frequency wind background. When high-frequency wind amplitude is larger than lowfrequency wind speed, the seasonal high-frequency and total LHFs increase with the enhancement of high-frequency wind amplitude. The extreme case is when low-frequency wind is zero. In this case, seasonal high-frequency and total LHFs always increase with the enhancement of high-frequency wind amplitude (black triangles and dots in Fig. 11a, $\mathrm{b}$, respectively). When high-frequency wind amplitude is smaller than low-frequency wind speed, the seasonal mean high-frequency LHF is zero (Fig. 11a), and total seasonal LHF is completely contributed by low-frequency LHF (Fig. 11b).

Combining the results of Figs. 10 and 11, the highfrequency wind amplitude is favorable for the increase of
Fig. 10 Variations of 90-day averaged a low-frequency (black squares), high-frequency (triangles) and $\mathbf{b}$ total (dots) LHF $\left(\mathrm{W} / \mathrm{m}^{2}\right)$ with low-frequency wind when high-frequency wind amplitude is fixed at a specific value $(0,2,4,6,8 \mathrm{~m} / \mathrm{s})$
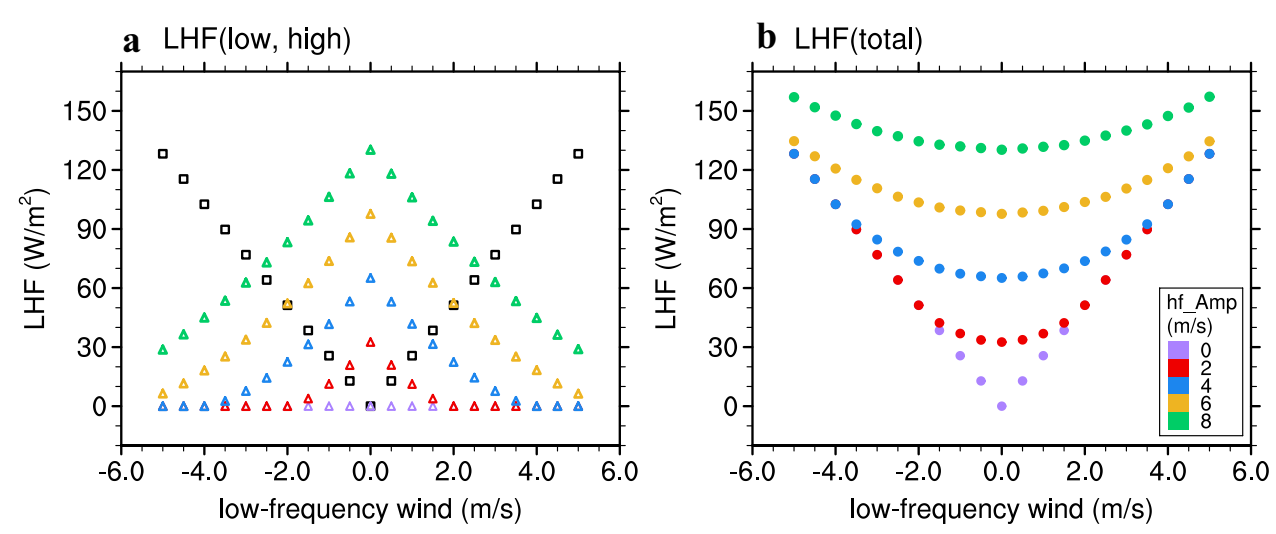

Fig. 11 Variations of 90-day averaged a high-frequency (triangles) and $\mathbf{b}$ total (dots) LHF $\left(\mathrm{W} / \mathrm{m}^{2}\right)$ with high-frequency wind amplitude when low-frequency wind is fixed at a specific value $(0,2$ or $-2,5$ or $-5 \mathrm{~m} / \mathrm{s}$ )
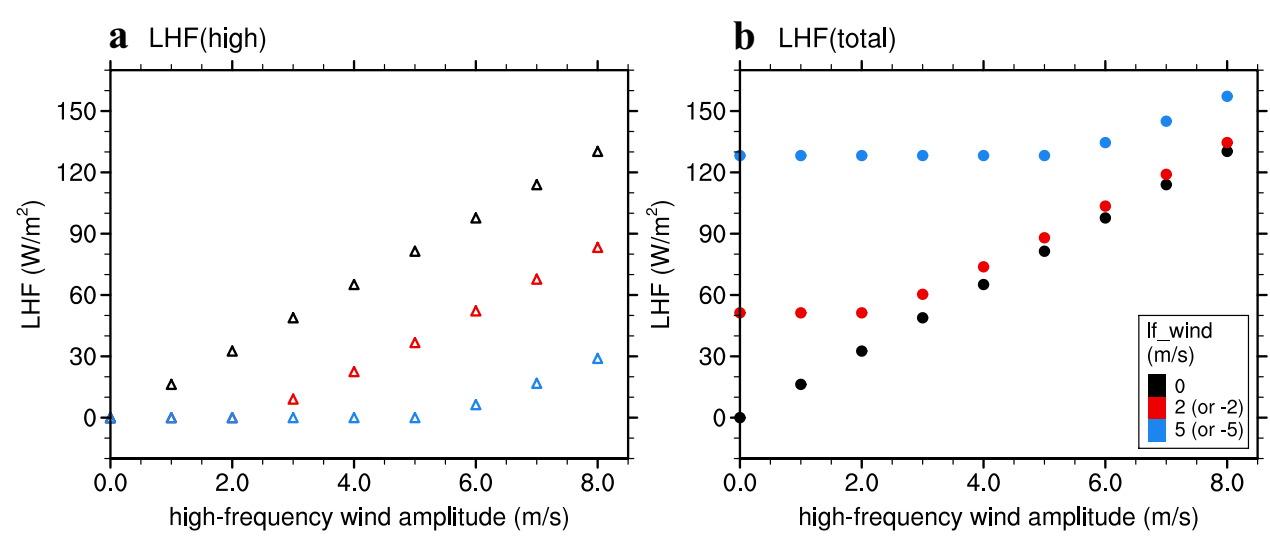
seasonal LHF only when it exceeds the low-frequency wind speed. Over the tropical WNP, climatological low-frequency surface wind in boreal summer is weak near the monsoon trough so that interannual variation of low-frequency surface wind speed has a large influence on the upscale feedback of high-frequency wind variability to seasonal LHF. Under the modulation of ENSO-related tropical Pacific SST anomalies, low-frequency surface wind speed and high-frequency wind intensity display opposite interannual variations, leading to prominent variations of seasonal high-frequency LHFs during ENSO events.

The above conceptual cases explain the weak interannual variation of seasonal LHF over the tropical WNP. During El Niño events, there are significant negative low-frequency LHF anomalies and positive high-frequency LHF anomalies over the tropical WNP that are induced by smaller low-frequency wind speed and stronger high-frequency wind intensity. The total seasonal LHF anomalies can be positive (e.g., in 2002) or negative (e.g., in 1997). Opposite anomalies can be observed during La Niña events. Low-frequency surface wind speed variation has opposite effects on seasonal lowand high-frequency LHF variations. The total LHF anomaly to some extent represents the relative contributions of lowfrequency wind speed and high-frequency wind intensity variations, so that it has weak interannual variability and small correlation with local SST change in the tropical WNP.

\section{Summary and Discussions}

The present study investigates interannual variations of seasonal mean low-frequency (>90-day) and high-frequency ( $\leq 90$-day) LHFs in boreal summer over the tropical WNP, which are associated with low- and high-frequency atmospheric variations, respectively. Contributions of surface wind speed and sea-air humidity difference to seasonal LHF anomalies are inspected. The effects of low-frequency surface wind speed and high-frequency wind intensity on the seasonal LHF variations are separately examined through a series of conceptual one-dimensional cases with different combinations of low-frequency surface wind and highfrequency wind intensity. The present results indicate the necessity to distinguish the roles of atmospheric variations on different time scales when inspecting their impacts on seasonal LHF variations and local seasonal SST change.

Our analysis shows that seasonal low- and high-frequency LHF variations over the tropical WNP are related to different factors. The low-frequency LHF anomalies are contributed by both low-frequency surface wind speed and sea-air humidity difference. The high-frequency LHF is mainly modulated by low-frequency surface wind speed and highfrequency wind intensity. It increases (decreases) when the low-frequency surface wind speed is smaller (larger) and high-frequency wind intensity is stronger (weaker). Contribution of high-frequency sea-air humidity difference is negligible. Due to the opposite dependence of low- and highfrequency LHF variations on low-frequency wind speed, seasonal low- and high-frequency LHFs have opposite contributions to the JJA SST change in the tropical WNP.

Based on results of conceptual cases with different combinations of JJA mean low-frequency wind and high-frequency wind intensity, it is revealed that the low-frequency wind and intensity of high-frequency wind variations can separately modulate the seasonal accumulated high-frequency LHFs. A larger (smaller) high-frequency wind amplitude is favorable for the increase (decrease) of seasonal upward LHF only when the high-frequency wind amplitude exceeds local low-frequency surface wind speed. Low-frequency wind can affect high-frequency LHF variation even with the highfrequency wind intensity fixed. When the low-frequency wind speed is smaller than high-frequency wind amplitude, the seasonal high-frequency LHF increases (decreases) with the weakening (enhancement) of low-frequency wind speed, which is opposite to its effect on low-frequency LHF. These results are consistent with the statistical analysis of observations in previous studies (Wang et al. 2020; Wu et al. 2020a, b).

Interannual variability of total LHF in boreal summer over the tropical WNP is much smaller than that of lowand high-frequency LHFs, and has a weak relationship with ENSO events and local seasonal SST change. This is attributed to the opposite variations of low- and high-frequency LHF variations. Under the modulation of seasonal tropical Pacific SST anomalies, opposite interannual variations are observed in variations of low-frequency surface wind speed and high-frequency wind intensity. The LHF anomalies associated with high-frequency atmospheric activities can be large enough to cancel the LHF anomalies induced by low-frequency wind variation, leading to small interannual variability of total LHF. During ENSO events, total seasonal LHF anomalies in summer over the tropical WNP can be positive or negative, depending on relative contribution of the opposite low- and high-frequency LHF anomalies. The total seasonal LHF anomaly reflects the net effects of lowand high-frequency atmospheric variations and thus have a weak relationship to local seasonal SST change in boreal summer.

Acknowledgements Comments of two anonymous reviewers are appreciated. This study is supported by the National Key Research and Development Program of China grant (2016YFA0600603) and the National Natural Science Foundation of China grants (41721004 and 41775080). The TropFlux data were obtained from https://incois. gov.in/tropflux/.

Author contributions Both authors contributed to the concept and design of the research. YW did the analysis. RW acquired the funding 
and supervised the research. YW prepared the draft. Both contributed to the revising and editing of the paper.

Funding The research is supported by the National Key Research and Development Program of China grant (2016YFA0600603) and the National Natural Science Foundation of China grants (41721004 and 41775080).

Availability of data and material The data in the present analysis are available for open access.

\section{Declarations}

Conflicts of interest There are no conflicts of interest to declare.

Consent for publication Both authors agree the submission and publication of the paper.

Open Access This article is licensed under a Creative Commons Attribution 4.0 International License, which permits use, sharing, adaptation, distribution and reproduction in any medium or format, as long as you give appropriate credit to the original author(s) and the source, provide a link to the Creative Commons licence, and indicate if changes were made. The images or other third party material in this article are included in the article's Creative Commons licence, unless indicated otherwise in a credit line to the material. If material is not included in the article's Creative Commons licence and your intended use is not permitted by statutory regulation or exceeds the permitted use, you will need to obtain permission directly from the copyright holder. To view a copy of this licence, visit http://creativecommons.org/licenses/by/4.0/.

\section{References}

Chen TC, Weng SP (1998) Interannual variation of the summer synoptic-scale disturbance activity in the western tropical Pacific. Mon Wea Rev 126(6):1725-1733

Chou MD (2000) Surface heat budgets and sea surface temperature in the Pacific warm pool during TOGA COARE. J Clim 13(3):634-649

Deser C, Wallace JM (1990) Large-scale atmospheric circulation features of warm and cold episodes in the tropical pacific. J Clim 3:1254-1281

Duvel JP, Vialard J (2007) Indo-Pacific sea surface temperature perturbations associated with intraseasonal oscillations of tropical convection. J Clim 20(13):3056-3082

Fairall CW, Bradley EF, Rogers DP, Edson JB, Young GS (1996) Bulk parameterization of air-sea fluxes for tropical ocean-global atmosphere coupled-ocean atmosphere response experiment. J Geophys Res Atmos 101(C2):3747-3764

Hu ZZ (1997) Interdecadal variability of summer climate over East Asia and its association with $500 \mathrm{hPa}$ height and global surface temperature. J Geophys Res Atmos 102:19403-19412

Huang RH, Lu L (1989) Numerical simulation of the relationship between the anomaly of the subtropical high over East Asia and the convective activities in the western tropical Pacific. Adv Atmos Sci 6:202-214

Huang RH, Sun FY (1992) Impacts of the tropical western Pacific on the East Asian summer monsoon. J Meteorol Soc Jpn 70:243-256

Kemball-Cook S, Wang B (2001) Equatorial waves and air-sea interaction in the boreal summer intraseasonal oscillation. J Clim 14:2923-2942
Kumar BP, Vialard J, Lengaigne M, Murty VSN, McPhaden MJ (2012) TropFlux: air-sea fluxes for the global tropical oceans-description and evaluation. Clim Dyn 38:1521-1543

Lau NC, Nath MJ (2000) Impact of ENSO on the variability of the asian-australian monsoons as simulated in GCM experiments. J Clim 13(24):4287-4309

Liu F, Zhou L, Ling J, Fu X, Huang G (2016) Relationship between SST anomalies and the intensity of intraseasonal variability. Theor Appl Climatol 124:847-854

Lu RY, Dong BW (2001) Westward extension of North Pacific subtropical high in summer. J Meteorol Soc Jpn 79(6):1229-1241

Meyers G, Donguy JR, Reed RK (1986) Evaporative cooling of the western equatorial Pacific Ocean by anomalous winds. Nature 323(6088):523-526

Nitta T (1987) Convective activities in the tropical western Pacific and their impact on the Northern Hemisphere summer circulation. J Meteorol Soc Jpn 64:373-390

Park JH, An SI (2014) The impact of tropical western Pacific convection on the North Pacific atmospheric circulation during the boreal winter. Clim Dyn 43:2227-2238

Park JH, An SI, Kug JS (2017) Interannual variability of western North Pacific SST anomalies and its impact on North Pacific and North America. Clim Dyn 49:3787-3798

Pond S, Fissel DB, Paulson CA (1974) A note on bulk aerodynamic coefficients for sensible heat and moisture fluxes. Bound-Lay Meteorol 6:333-339

Rasmusson EM, Carpenter TH (1982) Variations in Tropical sea surface temperature and surface wind fields associated with the southern oscillation/El Niño. Mon Wea Rev 110:354-384

Stevenson JW, Niiler PP (1983) Upper ocean heat budget during the Hawaii-to-Tahiti shuttle experiment. J Phys Oceanogr 13:1894-1907

Sui CH, Chung PH, Li T (2007) Interannual and interdecadal variability of the summertime western North Pacific subtropical high. Geophys Res Lett 34:L11701

Teng HY, Wang B (2003) Interannual variations of the boreal summer intraseasonal oscillation in the Asian-Pacific Region. J Clim 16:3572-3584

Waliser DE, Murtugudde R, Lucas LE (2004) Indo-Pacific Ocean response to atmospheric intraseasonal variability: 2 . boreal summer and the intraseasonal oscillation. J Geophys Res 109:C03030

Wang HJ, Chen HP (2012) Climate control for southeastern China moisture and precipitation: Indian or East Asian monsoon? J Geophys Res Atmos 117:D12109

Wang L, Chen GH (2018) Impact of the spring SST gradient between the tropical Indian Ocean and western Pacific on landfalling tropical cyclone frequency in China. Adv Atmos Sci 35:682-688

Wang YQ, Wu R (2020) Patterns and factors of interannual variations of boreal summer intraseasonal oscillation intensity over tropical western North Pacific. Clim Dyn 54:2085-2099

Wang B, Wu R, Fu X (2000) Pacific-East Asian teleconnection: how does ENSO affect East Asian climate? J Clim 13(9):1517-1536

Wang B, Wu R, Li T (2003) Atmosphere-warm ocean interaction and its impacts on Asian-Australian monsoon variation. J Clim 16(8):1195-1211

Wang SY, L'Heureux M, Chia HH (2012) ENSO prediction one year in advance using western North Pacific sea surface temperatures. Geophys Res Lett 39:L05702

Wang YQ, Wu R, Jiao Y (2020) Upscale feedback of high-frequency winds on seasonal SST change over the tropical western North Pacific during boreal summer. Clim Dyn 55:2439-2451

Webster PJ, Holland GJ, Curry JA, Chang HR (2005) Changes in tropical cyclone number, duration and intensity in a warming environment. Science 309:1844-1846 
Woolnough SJ, Slingo JM, Hoskins BJ (2000) The relationship between convection and sea surface temperature on intraseasonal timescales. J Clim 13:2086-2104

Wu R (2018) Feedback of 10-20-day intraseasonal oscillations on seasonal mean SST in the tropical Western North Pacific during boreal spring through fall. Clim Dyn 51:4169-4184

Wu R, Cao X (2017) Relationship of boreal summer 10-20-day and 30-60-day intraseasonal oscillation intensity over the tropical western North Pacific to tropical Indo-Pacific SST. Clim Dyn 48:3529-3546

Wu R, Kirtman BP (2007) Regimes of seasonal air-sea interaction and implications for performance of forced simulations. Clim Dyn 29:393-410

Wu R, Song L (2018) Spatiotemporal change of intraseasonal oscillation intensity over the tropical Indo-Pacific Ocean associated with El Niño and La Niña events. Clim Dyn 50:1221-1242

Wu R, Hu ZZ, Kirtman BP (2003) Evolution of ENSO-related rainfall anomalies in East Asia. J Clim 16(22):3742-3758

Wu R, Huang G, Du ZC, Hu KM (2014) Cross-season relation of the South China Sea precipitation variability between winter and summer. Clim Dyn 43(1):193-207

Wu R, Wang YQ, Jiao Y (2020a) High frequency wind-related seasonal mean latent heat flux changes. Clim Dyn 55:3269-3287

Wu R, Jiao Y, Wang YQ, Jia XJ (2020) High frequency windrelated seasonal mean latent heat flux changes over the tropical
Indo-western Pacific in El Niño and La Niña years. J Geophys Res Atmos. https://doi.org/10.1029/2020JD032954

Xie SP, Hu KM, Hafner J, Tokinaga H, Du Y, Huang G, Sampe T (2009) Indian Ocean capacitor effect on Indo-western Pacific climate during the summer following El Niño. J Clim 22:730-747

Yoo SH, Ho CH, Yang S, Choi HJ, Jhun JG (2004) Influences of tropical western and extratropical Pacific SST on east and southeast Asian climate in the summers of 1993-94. J Clim 17:2673-2687

Zhan R, Wang Y, Wen M (2013) The SST gradient between the southwestern Pacific and the western Pacific warm pool: A new factor controlling the northwestern Pacific tropical cyclone genesis frequency. J Clim 26:2408-2415

Zhou TJ, Yu RC (2005) Atmospheric water vapor transport associated with typical anomalous summer rainfall patterns in China. $\mathrm{J}$ Geophys Res Atmos 110:D08104

Zhou XY, Lu RY, Chen GH, Wu L (2018) Interannual variations in synoptic-scale disturbances over the western North Pacific. Adv Atmos Sci 35:507-517

Publisher's Note Springer Nature remains neutral with regard to jurisdictional claims in published maps and institutional affiliations. 